IZA DP No. 7769

Does Patience Matter for Marriage Stability?

Some Evidence from Italy

Maria De Paola

Francesca Gioia

November 2013 


\title{
Does Patience Matter for Marriage Stability? Some Evidence from Italy
}

\author{
Maria De Paola \\ University of Calabria \\ and IZA \\ Francesca Gioia \\ University of Calabria
}

Discussion Paper No. 7769

November 2013

\author{
IZA \\ P.O. Box 7240 \\ 53072 Bonn \\ Germany \\ Phone: +49-228-3894-0 \\ Fax: +49-228-3894-180 \\ E-mail: iza@iza.org
}

Any opinions expressed here are those of the author(s) and not those of IZA. Research published in this series may include views on policy, but the institute itself takes no institutional policy positions. The IZA research network is committed to the IZA Guiding Principles of Research Integrity.

The Institute for the Study of Labor (IZA) in Bonn is a local and virtual international research center and a place of communication between science, politics and business. IZA is an independent nonprofit organization supported by Deutsche Post Foundation. The center is associated with the University of Bonn and offers a stimulating research environment through its international network, workshops and conferences, data service, project support, research visits and doctoral program. IZA engages in (i) original and internationally competitive research in all fields of labor economics, (ii) development of policy concepts, and (iii) dissemination of research results and concepts to the interested public.

IZA Discussion Papers often represent preliminary work and are circulated to encourage discussion. Citation of such a paper should account for its provisional character. A revised version may be available directly from the author. 
IZA Discussion Paper No. 7769

November 2013

\section{ABSTRACT}

\section{Does Patience Matter for Marriage Stability? Some Evidence from Italy}

Time preferences can affect divorce probability both affecting the quality of the match and affecting the spouses' reactions to negative shocks. We analyze the relationship between time preferences and divorce decisions using data from the Italian Survey on Household Income and Wealth, which provides a measure of time preferences based on a hypothetical financial situation in which individuals have to decide how much money to give up in order to receive a certain amount of money today instead of in one year's time. Controlling for a number of individual and family characteristics, we find that an increase in impatience of one standard deviation increases the probability of experiencing divorce by almost one percentage point. Our results are not affected by reverse causality problems and are robust when controlling for individual risk attitudes. We also find that more risk averse individuals are less likely to experience divorce.

JEL Classification: I20, D03, D91, J01

Keywords: divorce, time preferences, impatience, risk aversion

Corresponding author:

Maria De Paola

Department of Economics and Statistics

University of Calabria

87036, Arcavacata di Rende (CS)

Italy

E-mail:m.depaola@unical.it

\footnotetext{
* We would like to thank for useful comments Vincenzo Scoppa, Roberto Veneziani, Marco Alberto De Benedetto, Fernando Puzzo and seminar participants to the Italian Association of Labour Economists conference, Rome, 2013. Financial support from Regione Calabria (European Social Fund) is gratefully acknowledged.
} 
The chief thing in married life is patience... not love but patience. Anton Čechov, The duel, 1891

\section{Introduction}

In recent years an increasing body of economic literature has tried to include, both in theoretical models and in empirical analyses, a more complex psychological dimension of individual decisions. A wide range of psychological traits have been found to be strong predictors of lifetime outcomes and success in life. For many outcomes psychological traits seem to be just as predictive as cognitive skills (Almlund et al., 2011).

Among psychological traits, the ones that have mainly attracted economists' interest are those reflecting two important dimensions of the utility function: risk aversion and time preferences. A large number of empirical and experimental works confirms the relevance of inter-temporal and risk preferences for a very large number of domains such as education, (Belzil and Leonardi, 2007; Caner and Okten, 2010; Castillo et al. 2011; Cadena and Keys, 2011; De Paola and Gioia, 2012, 2013), labour market outcomes (Della Vigna and Paserman, 2005; Drago, 2006; Ahn, 2010; Dohmen et al., 2010; Dohmen and Falk, 2011; Pollmann et al. 2012), health (Sutter et al., 2011; Golsteyn et al., 2012), immigration (Jaeger et al., 2010). Much less studied is the role of these variables on marriage, divorce and fertility.

Family breakdown has important implications for a number of societal outcomes, such as inequality and child wellbeing. Therefore, the understanding of its determinants is very important, though still limited. The existing literature has mainly focused on a number of socio-economic factors, such as age at marriage, education, unemployment (Lehrer, 2008), while little attention has been paid to the role played by psychological traits and preferences (Lundeberg, 2013).

As regards risk attitudes, Spivey (2010) and Smidth (2008) analyze their role in shaping marriage decision and show that risk-tolerant women are more likely to delay marriage. In addition, Smidth (2008) finds that higher tolerance for risk is positively correlated to earlier births at young age. Light and Ahn (2010) focus, instead, on the relationship between risk preferences and divorce, finding that, conditional on the expected gains to marriage and divorce, the probability of divorce increases with relative risk tolerance.

In this paper, we contribute to this literature by focusing on the relationship between time preferences and marriage stability. Even if the economic theory typically models divorce decision as a choice involving a trade-off between costs and benefits occurring in different periods of time, individual time preferences are usually ignored. Compton (2009) is the only attempt to consider the role of time preferences on divorce. She presents a game theoretical model showing that following a negative shock whose temporary or permanent nature is uncertain for the spouses at the time it occurs, patient individuals are more likely to remain in a marriage relationship, hoping that the shock is temporary. 
Despite the lack of academic work on the relationship between time preferences and marriage stability, common wisdom considers patience as a key ingredient for marital success. Marriage stability is often the result of the spouses' willingness to make short term "sacrifices" for the long term viability of their marriage. Patience is likely to improve everyday interactions and communication within the couple with positive effects on the duration of the relationship. Time preferences can also affect the way in which individuals react to unanticipated shocks that deteriorate their relationship. More patient individuals may be more inclined to sustain the immediate costs deriving from staying in a troubled marriage and wait for an improvement in the relationship. They might also be more prone to invest in order to re-establish harmony within the couple.

Time preferences can affect marriage stability also through the initial quality of the match. As suggested in the seminal work by Becker, Landes and Michael (1977), the choice of search effort is principally an investment decision involving immediate costs and future gains in terms of better marriage opportunities. Then, impatient individuals are more likely to invest less and end up with a worse match. Furthermore, as in job search models (Della Vigna and Paserman, 2005), impatience can affect the quality of the match also by driving the reservation policy chosen by each individual (Burdett and Cole, 1999). The quality of the match, in turn, will affect the probability of divorce as unanticipated shocks are less destabilizing if partners are well matched.

Investigating the relationship between time preferences and marriage/divorce decisions is often hampered by the lack of appropriate data. In this paper, we use data from Italy, a country that, notwithstanding its long tradition of a stable family system, is now experiencing a progressive rise in divorces. More precisely, we use data from the 2004 and 2010 waves of the Survey on Household Income and Wealth (SHIW). The use of these data has the advantage of providing a direct measure of time preferences. This measure is based on a hypothetical financial situation in which individuals have to decide how much money to give up in order receiving a certain amount of money today instead of in one year's time. To avoid reverse causality problems that may emerge when using measures of impatience computed in the same moment in which marital status is observed, we have restricted our sample to the panel component of individuals for which we have observations both in 2004 and in 2010. We focus on individuals who were married in 2004 and look at their probability of divorcing in the time interval 20042010. Our measure of impatience and all our controls are computed using answers to the 2004 survey.

We estimate a probit model for the probability of divorcing. Controlling for an array of variables aimed at capturing the gains to marriage and divorce (such as education gap, age cohort dummies, age gap, family composition, individual and family income, area of residence, occupation industry dummies, family background, etc.), we find that time preferences play an important role in the decision to divorce. More impatient individuals are more likely to experience divorce: an increase in impatience of one standard deviation increases the probability of divorcing by almost one percentage point. These results are robust to different specifications of our model and to the inclusion of different controls. 
As time preferences might be correlated to risk aversion, our results may be driven by the fact that more patient individuals are more risk averse (De Paola, 2012) and, as shown by Light and Ahn (2010), more risk averse individuals are less likely to experience separation or divorce. Unfortunately, the 2004 wave of the SHIW does not provide any information on individuals' risk attitudes. This information is instead available in the 2010 wave of the survey, which poses individuals with a question asking them to choose the amount of money they would like to invest in a risky hypothetical lottery. Then, we use data from this wave to analyse the relationship between time preferences and marriage stability controlling for risk attitudes. Taking the level of risk aversion constant, time preferences continue to play a role and more impatient individuals are more likely to experience a marriage breakdown. Although in such analysis the measures of time preferences and risk attitudes are computed at the same moment in which the marital status is observed, results from previous estimates (which do not suffer of reverse causality problems) reassure us that the relationship between time and risk preferences and divorce is unlikely to derive exclusively from the effect that marital condition produces on preferences.

Our analysis contributes to the emerging literature on the effect of time and risk preferences on marriage stability by proving additional evidence on this issue and by improving on some aspects. Our results are in line with those emerging from Compton (2009) who, considering the U.S. National Longitudinal Survey of Youth, finds that patient individuals are less likely to divorce especially in the earlier years of marriage. One advantage of our study is that we use a direct measure of time preferences, whilst Compton relies on indirect measures of time preferences, such as smoking, contraceptive use and the assessment of the interviewer on whether or not the respondent was impatient or restless. In addition, we control for a direct measure of risk aversion. To the best of our knowledge, this is the first study that jointly considers the role of time and risk preferences on divorce.

By controlling for risk aversion we both check that our results are not driven by the fact that higher discount rates are correlated to a lower degree of risk aversion and analyse the effect that risk aversion produces on divorce probability. Our results confirm those found by Light and Ahn (2010) for US, showing that less risk averse individuals are more likely to experience separation or divorce.

We also contribute to the small literature investigating divorce determinants in Italy. We find that couples with children and living in the southern part of the country are less exposed to divorce. On the other hand, individuals with higher individual income and living in large towns show a higher divorce probability. Women who were head of household in 2004 are more likely to divorce compared to men in the same position, confirming that female economic independence is a crucial determinant of divorce decisions.

The paper is organized as follows. Section two describes the data used in the empirical analysis. Section three presents the probit estimates of the probability of experiencing separation or divorce. In Section four we check the robustness of our results using a larger sample which also allows us to control for risk aversion. Section five concludes. 


\section{Data and descriptive statistics}

In Italy divorce was introduced by law in 1970. Since then, marital separation and divorce rates have been gradually rising in Italy, especially among couples between 35 and 40 years old. In 1995, the percentage of marriages ending with a separation or a divorce was of 2.38, while in 2010 this percentage has risen to 4.89. ${ }^{1}$ In spite of this rising trend, Italy still displays one of the lowest levels of marriage dissolution in Europe: the Eurostat divorce statistics report a crude divorce rate of 0.9 for Italy (which translates in about $4.5 \%$ of couples that experience divorce/separation) in 2010, which is followed only by the Former Yugoslav Republic of Macedonia and Montenegro (0.8) and Ireland (0.7); the highest divorce rate for the same year belongs to Lithuania (3.0).

Aside from cultural and religious factors, there are other potential explanations for such a low divorce rate in Italy. First of all, it may be due to the fact that in Italy it is not easy to divorce: couples are required to be legally separated for three continuous years before their divorce is finalized. The Italian law defines two kinds of legal separation: separation by mutual consent or judicial separation. In the first case, the decision to separate is consensual, whilst, if there is no agreement between the spouses, each spouse can file recourse for judicial separation. A separation decree may be granted when there are facts which make intolerable the continued cohabitation of the couple or things which are averse to the mental health or physical wellbeing of children in the household. The legal separation has the effect of suspending the legal consequences of marriage until reconciliation or divorce is reached. Therefore, the low divorce rate characterizing Italy can be also due to the fact that a number of separations do not end up in a divorce. This is typically not due to the couple reconciliation, but instead to the fact that the couple decides to remain separated in order to spare the costs deriving from the legal proceeding (divorce is strictly necessary only if one of the partners wants to remarry). ${ }^{2}$ For this reason, when studying marriage stability in Italy, it is useful to focus not only on divorces but also on separations.

To investigate the relationship between marriage stability and time preferences we use data from the Survey on Household Income and Wealth (SHIW) ${ }^{3}$, which is a nationally representative survey that has been conducted every two years by the Bank of Italy since 1977. The SHIW provides detailed information on the personal and demographic characteristics of the individuals of each household (status in household, gender, age, educational qualifications, marital status, region of residence) and on their working activity (employment status, type of occupation, industry, number of work experiences, type of contract, average weekly hours of work, earnings, wealth). Most importantly, worldwide this is one of the few surveys providing information on time and risk preferences.

The other main sources of data on individual time and risk preferences include the German SocioEconomic Panel (GSEP) and the National Longitudinal Survey of Youth (NLSY) for US. However, in all

\footnotetext{
${ }^{1}$ For a more detailed analysis see the 2012 report “Separations and divorces in Italy” of the Italian National Institute of Statistics (ISTAT), www.istat.it

${ }^{2}$ As reported by Salvini and Vignoli, 2011, of the total number of legal separations obtained in 1995, only 60\% ended in a divorce during the following decade.

3 The detailed questionnaire, the data and further details regarding the Survey on Household Income and Wealth are available on the website of the Bank of Italy, http://www.bancaditalia.it/statistiche/indcamp/bilfait.
} 
the available surveys, questions aimed at eliciting time and risk preferences have been comprised only recently. For example, the NLSY includes questions on risk aversion starting from 1993, while both the GSEP and the SHIW pose questions on time and risk preferences starting from 2004 and 2000 respectively. When using the data at the purpose of investigating divorce decisions, this leads to some important problems. In fact, we would need measures of time and risk that are predetermined with respect to the outcome variable. Instead, these data allow to observe marriage histories starting from many decades ago, but individual time and risk preferences only refer to more recent years. For example, Light and Ahn (2010) analyse divorce decisions using NLSY data from 1979 to 2004, but they have information on risk preferences only starting from 1993. This poses a serious problem of reverse causality as the ability to delay gratifications may be not entirely an inborn personality trait (see Perez-Arce, 2011) and the marital status may play a role in shaping individual risk (and time) preferences.

To handle this problem in our analysis we compute our measure of impatience and our control variables using the 2004 wave of the SHIW ${ }^{4}$ and then we restrict our sample to the panel component of heads of household for which we have observations both in 2004 and in 2010. We only consider heads of household, defined as the subject who is responsible of the household's economic decisions, since the survey question we use to compute the measure of time preferences was posed only to these subjects. From this sample we drop individuals who were not married in 2004, ending up with 1,723 observations. In this way we are able to use time preferences revealed in 2004 to estimate the probability that the individual experiences separation or divorce after 2004. Since all individuals in our sample were married in 2004 and our variable of interest is predetermined with respect to the outcome variable, our results should not be biased by reverse causality problems.

Our dependent variable is DivorceAfter2004, a dummy variable taking the value of 1 if the marital status of the individual results "separated or divorced" in 2010 but s/he was married in 2004 and the value of 0 for people who result married both in 2004 and 2010; 2.7\% of the sample has divorced after 2004.

The structure of the SHIW question on civil status, which places both "separated" and "divorced" within the same alternative ${ }^{5}$, reflects the fact that in Italy, as explained above, an important indicator of family dissolution is represented by separations. We do not know whether these separations and divorces were decided by mutual consent. However, from the 2012 report of the Italian National Institute of Statistics (Istat) it emerges that the type of proceeding mainly chosen by couples is consensual separation: in 2010, $85.5 \%$ of separations and $72.4 \%$ of divorces were decided by mutual consent (ISTAT, 2009). ${ }^{6}$ The information on which of the partners requested the proceedings (in case of judicial separation) is not

\footnotetext{
${ }^{4}$ In the 2000 survey the question on time preferences was posed to only a half of the panel sample. This jointly to a number of missing values considerably reduces the sample and makes it unsuitable for our research project.

5 Respondents are asked to choose their marital status among four alternatives: a) married; b) single; c) separated/divorced; d) widow/er.

${ }^{6}$ Until 2005, sole custody of minors was mainly awarded to the mother. In 2006, Law 54/2006 introduced the provision of joint custody of minor children as an ordinary procedure. In 2009, $86.2 \%$ of separations with children were with joint custody, as opposed to $12.2 \%$ in which custody of the children was awarded exclusively to the mother.
} 
crucial for our analysis since the divorce decision is likely to be influenced by both the individual time preferences and those of his/her partner.

The SHIW data allow to compute indicators of time preferences in a direct way by using the answers to a question of the 2004 wave posed only to the heads of household inquiring their behaviour in a hypothetical financial situation in which they had to decide how much money to give up in order to receive a certain amount of money today instead of in one year's time. To be more precise, respondents are asked the following question: "You have won the lottery and will receive a sum equal to your household's net yearly revenue. You will receive the money in a year's time. However, if you give up part of the sum you can collect the rest of your win immediately”. After the description of the hypothetical situation, the respondent is routed in a series of questions about the percentage s/he would be willing to give up. Among the available alternatives for the percentage of the sum that respondents would be willing to give up to have immediately the money won there are $0,2,3,5,10$ or 20 percent.

Table 1 shows the distribution of heads of household by reported percentage of the win that they would like be give up to get the money immediately. About $26 \%$ of respondents refuse to give up any amount of money, waiting to have the whole amount the following year. 5.92\% of respondents decide to give up 2 percent and about 9.63\% decide to give up 3 percent, while $31.11 \%$ of them choose to give up 5 percent. Finally, 19.21\% and 8.30\% of heads of household give up 10 and 20 percent, respectively. In terms of the Discounted Utility Model $^{7}$, the percentage given up in order to have money immediately represents the discount rate of the respondent.

\begin{tabular}{lcc}
\multicolumn{3}{c}{ Table 1. Time preferences: percentage given up to have money immediately } \\
\hline \hline Percentage & Frequencies & $\%$ \\
\hline 0 & 445 & 25.83 \\
2 & 102 & 5.92 \\
3 & 166 & 9.63 \\
5 & 536 & 31.11 \\
10 & 331 & 19.21 \\
20 & 143 & 8.30 \\
& 1,723 & 100.00 \\
\hline \hline
\end{tabular}

We use the answers to this question of the 2004 survey to build an indicator of time preferences: DiscountRate2004 taking values from 0 (for patient respondents who decided to give up nothing, waiting to have the whole amount of the win in one year) to 0.2 (for really impatient respondents who would give up 20 percent). Since we compute our indicator of time preferences before the realization of the outcome of interest, we avoid the problem of reverse causality: having divorced after 2004 has no role in shaping the level of impatience in 2004. Individuals in the sample have an average discount rate of about 0.06 .

As underlined by Ventura (2003, p. 308), the measures of inter-temporal attitudes (as well as other personal traits) collected through surveys have some advantages with respect to experimental data. Firstly, the number of observations is typically greater because a survey allows the collection of information on

\footnotetext{
${ }^{7}$ For a detailed description of the Discounted Utility Model see Samuelson (1937).
} 
more individuals compared to the participants in experimental studies. Secondly, problems related to the reliability of the indicators are less relevant for analyses based on broad surveys (such as SHIW): individuals are asked to answer many questions about their economic situation, financial assets, properties, loans, consumption and investment decisions, which allows them to better link the hypothetical situation with their real life.

The measure of time preferences we have obtained seems quite reliable: it behaves in the same way as those emerging from a number of recent papers on the subject. In particular, looking at cognitive abilities, it emerges that individuals with a higher level of education tend to be less impatient compared to respondents who invest less in education (the correlation between DiscountRate2004 and Education is equal to -0.0874 , statistically significant at the 1 percent level). Results that are consistent with the literature (Golsteyn et al., 2012) emerge also when looking at family background: individuals whose parents are more educated tend to be less impatient than respondents whose parents have a lower level of education (the correlation between DiscountRate2004 and Parents_Education is equal to -0.0445, statistically significant at the 10 percent level). As in Ventura (2003), people residing in the North of Italy seem to be more patient than people living in regions of the Centre (the correlation between DiscountRate and North is equal to -0.0676, statistically significant at the 1 percent level); on the contrary, individuals living in the South have a higher level of impatience (the correlation between DiscountRate2004 and South is equal to 0.1570 , statistically significant at the 1 percent level). The gender analysis is not very relevant in our study due to the particular features of the women present in our sample. Indeed, they are heads of household, therefore they do not represent the whole female population (the correlation between DiscountRate2004 and the dummy Female is equal to 0.0471, statistically significant at the 5 percent level). In addition, DiscountRate2004 is negatively correlated with savings (-0.0964, statistically significant at the 1 per cent level), which is a variable that has been proven to strongly react to time preferences.

Table 2 reports the summary statistics for the variables used in the analysis. About $23 \%$ of individuals in the sample are woman. Respondents are 53.65 years old on average. To consider the effect produced by changes in cultural attitudes and customs occurring overtime we have built 5 dummy variables for birth cohorts (born before 1940, born in the period 1941-1950, 1951-1960, 1961-1970 and born after 1970); the majority of the sample is born before 1960 while only about 19 and 5 percent of respondents are born in the sixties or after 1970, respectively. The majority of the sample resides in the North of Italy (about 44\% against 37\% and 19\% who are resident in the South and in the Centre, respectively). About $31 \%$ of the sample resides in a municipality with less than 20,000 inhabitants. As far as occupation industries are concerned, about $3 \%$ of the sample work in agriculture, $17 \%$ in industry and $16 \%$ in the public administration sector; about $17 \%$ work in other sectors while the remaining are retired or not employed.

With the aim of capturing heterogeneity in match quality, we use a large number of variables to control for the expected gains to marriage and divorce. The variable Age Gap, computed using the years of 
birth of the partners of each couple indicates the absolute value of the difference in the husband's and wife's age, which has a mean value of 5.41. Respondents have studied on average for 9.56 years. We use the information on the couple's education level to build the variable Education Gap, which is the absolute value of the difference in the number of years of education acquired by the spouses. This variable has a mean value of 2.14 .

Table 2. Descriptive statistics for the sample of heads of household

\begin{tabular}{|c|c|c|c|c|}
\hline Variables & Mean & Std. Dev & Min. & Max. \\
\hline DiscountRate2004 & 0.0554 & 0.0553 & 0 & 0.2 \\
\hline DivorceAfter2004 & 0.0273 & 0.1629 & 0 & 1 \\
\hline Female & 0.2263 & 0.4186 & 0 & 1 \\
\hline Age & 53.6489 & 12.9862 & 18 & 92 \\
\hline Born before or in 1940 & 0.2455 & 0.4305 & 0 & 1 \\
\hline Born in $1941-1950$ & 0.2577 & 0.4375 & 0 & 1 \\
\hline Born in 1951-1960 & 0.2589 & 0.4381 & 0 & 1 \\
\hline Born in $1961-1970$ & 0.1880 & 0.3909 & 0 & 1 \\
\hline Born after 1970 & 0.0499 & 0.2178 & 0 & 1 \\
\hline North & 0.4382 & 0.4963 & 0 & 1 \\
\hline South & 0.3680 & 0.4824 & 0 & 1 \\
\hline Centre & 0.1938 & 0,3954 & 0 & 1 \\
\hline Small Municipality & 0.3064 & 0.4611 & 0 & 1 \\
\hline Education & 9.5572 & 4.2926 & 0 & 20 \\
\hline Age Gap & 5.4115 & 4.3760 & 0 & 28 \\
\hline Education Gap & 2.1416 & 2.5587 & 0 & 13 \\
\hline Kids under 11 & 0.1822 & 0.3861 & 0 & 1 \\
\hline Male-kids & 0.1404 & 0.3476 & 0 & 1 \\
\hline Individual Net Labour Income & $15,284.13$ & $11,788.29$ & $-6,566$ & 125,000 \\
\hline Family Net Labour Income & $26,015.81$ & $17,531.98$ & $-5,705.95$ & 255,000 \\
\hline Individual Share Family Income & 0.6266 & 0.3238 & -0.4227 & 1 \\
\hline Agriculture & 0.0273 & 0.1629 & 0 & 1 \\
\hline Industry & 0.1706 & 0.3763 & 0 & 1 \\
\hline Public Administration & 0.1608 & 0.3674 & 0 & 1 \\
\hline Other Sector & 0.1683 & 0.3743 & 0 & 1 \\
\hline Individual Net Total Income & $22,689.41$ & $17,377.28$ & $-5,693.50$ & 245,671 \\
\hline Family Net Total Income & $33,421.1$ & $22,533.9$ & $-5,693.504$ & $262,007.1$ \\
\hline Individual Share Family Total Income & 0.7015 & 0.2677 & -0.2160 & 1 \\
\hline Individual Net Labour Income Square & $372,487.7$ & 875,156 & 0 & $15,625,000$ \\
\hline Family Net Labour Income Square & $984,014.6$ & $2,378,609$ & 0 & $65,025,000$ \\
\hline Individual Predicted Income & $11,711.19$ & $5,205.12$ & $-4,121.33$ & $27,545.63$ \\
\hline Family Predicted Income & $23,248.18$ & $10,366.72$ & $-2,776.28$ & $62,143.93$ \\
\hline Parents' Education & 4.5053 & 3.4534 & 0 & 18 \\
\hline Father in Agriculture & 0.2900 & 0.4539 & 0 & 1 \\
\hline Father in Industry & 0.2395 & 0.4269 & 0 & 1 \\
\hline Father in Public Administration & 0.1492 & 0.3565 & 0 & 1 \\
\hline
\end{tabular}

The data at hand also provide information on the family composition of the individual prior to separation/divorce. To describe the family composition we consider: the dummy variable Kids Under 11 indicating whether the couple has any child with an age lower or equal to 10 years and the dummy variable Male-Kids which takes the value of 1 if at least one of the kids younger than 11 years is male. Controlling for the presence of kids is important to capture marriage-specific capital (Becker, 1974; Becker et al., 1977; Weiss and Willis, 1997). In addition, the presence of a male child has been found to reduce the probability of divorce (Morgan and Pollard, 2002; Lundberg and Rose, 2003). About 18\% of the interviewed heads of household has at least one kid aged ten or below in 2004 and for 14\% of respondents at least one of these children is male. The number of kids in the household ranges from 0 to 5 , with an average number of 0.86 . Unfortunately, we are not able to control whether the couple has any 
child born outside the marriage and living in the household because the 2004 wave does not contain such information.

Our data set also provides information on the individual and family economic conditions prior to divorce. Economic variables are important when looking at couple dynamics: on the one hand, family income captures part of the benefits of marriage because the higher the income that the family earns, the higher its level of consumption; on the other hand, individual income defines the share of total income contributed by the respondents and therefore hishher economic independence (Oppenheimer, 1997; Moffitt, 2000; Light and Ahn, 2010). As far as income is concerned, we have information on the income earned by the head of household in the year preceding the survey (i.e. 2003), which includes both labour income and income from financial and real assets, and on the total income of the family. We restrict our attention on individual and family net labour income, ${ }^{8}$ computed as the sum of payroll income, pensions and net transfers, and net self-employment income, and build three economic indicators: Individual Net Labour Income, which is on average €15,284.13; Family Net Labour Income, with a mean value of $€ 26,015.81$, and Individual Share Family Income, which represents the share of the family net labour income contributed by the head of the household. On average, heads of household contribute for $63 \%$ of the net labour family income.

In models looking at the determinants of the decision of ending a marriage relationship, however, the net labour income of the individual can be endogenous: individuals' beliefs about a future divorce can alter their labour supply decisions (Greene and Quester, 1982; Johnson and Skinner, 1986; Stevenson, 2007). In order to solve this potential endogeneity problem, we follow Light and Ahn (2010) and compute individual's predicted labour income using gender, age, age-squared, age-cubed, education attainments, dummies for area of residence, a dummy for the presence of children aged 10 years or below, a dummy for the presence of male children aged 10 or below and industry dummies. Individual predicted labour income is on average $€ 11,711.19$, and family predicted labour income, given by the sum of the spouses' predicted income, is on average $€ 23,248.18$. Furthermore, we compute also the square values of individual and family net labour income and measures of individual and family net total income (i.e. labour income plus property income from real-estate and financial assets) and of the share of the net total income contributed by the head of household. On average, heads of household contribute for $70 \%$ of the net total family income, which is on average $€ 33,421.10$.

As regards family background, the parents of the individuals included in our sample have on average 4.5 years of education and they mainly work/ed in the agriculture sector (29\%, against $24 \%$ in industry, $15 \%$ in public administration and the remaining in other sectors).

\footnotetext{
${ }^{8}$ Since in our analysis we consider net income figures, the income variables can assume negative values.
} 


\section{Impatience and Divorce: Probit estimates}

Individual level of impatience is a key determinant of decisions involving a trade-off between costs and benefits occurring in different periods of time. In divorce decisions there are different channels through which these trade-offs may operate: 1) mate search activity - impatient individuals, in order to avoid the immediate costs arising from search activity, prefer to invest less in the research of a partner and to lower their reserve "standard", ending up with a lower initial quality of the match -; 2) daily life of the couple - living together as a couple means spending time with a partner that has habits and tastes, which in some cases diverge from personal ones; this entails small daily compromises, which typically involve immediate costs for the delayed benefits of a long and stable relationship -; 3) negative shocks which affect the equilibrium of the marriage - staying in a troubled marriage implies sustaining the immediate costs of the shock in order to obtain the future benefits deriving from an improvement in the relationship.

In this section, we examine the relationship between individual time preferences and the probability of divorcing. In all estimates our dependent variable is the dummy variable DivorceAfter2004, which takes the value 1 if the interviewed head of household has experienced separation or divorce ${ }^{9}$ after 2004 (his/her civil status is separated or divorced in 2010 but married in 2004) and 0 otherwise.

Given the binary nature of the outcome of interest, we use the following probit regression model:

$$
P(\text { DivorceAfter } 2004=1 \mid X)=\Phi(Z)
$$

where $P$ denotes the probability of experiencing divorce, $X$ is a vector of all the regressors of the model, $\Phi$ is the Cumulative Density Function of the standard normal distribution that makes it possible to obtain a realistic value for the probability ( $>0$ and $<1$ ) and a non-linear relationship between the probability and the explanatory variables, and the ' $z$-scores' vector $Z$ is defined as follows:

$$
Z=\Phi^{-1}(P)=\alpha+\beta \text { DiscountRate } 2004+\gamma D
$$

with $D$ representing a vector of all the other explanatory variables except DiscountRate2004, and $\beta$ and the vector $\gamma$ the unknown parameters.

All regressors are measured in 2004. Table 3 shows the probit model estimates of the probability of divorce for five different specifications. The reported coefficients represent the average marginal effect of each regressor on the probability to divorce after 2004. The explanatory variables we control for in our analysis are those typically used in the literature studying marriage stability and divorce decisions (Light and Ahn, 2010) with the exception of some variables, such as race, ethnicity, which are not relevant in our sample (in Italy the population is quite homogeneous both in race and ethnicity), and others, such as date of marriage, presence of children born before the marriage or born from another partner, which are not available in the 2004 wave of the SHIW.

The first column of Table 3 examines the effect of time preferences on the probability of being separated or divorced without other controls. We find a positive relationship between impatience and the

\footnotetext{
${ }^{9}$ The label divorce is therefore used in a broad sense to indicate both couples which are separated and couples which are divorced.
} 
probability of divorce: an increase in the level of impatience of one standard deviation increases by almost 1 percentage point the probability of being divorced, with an effect that is statistically significant at the 1 percent level.

In the second column we add among controls some individual characteristics such as gender, AgeGap, EducationGap, birth cohort dummies, area of residence dummies and a dummy variable for individuals residing in villages with less than 20,000 inhabitants. Also controlling for these variables, we find that the individual discount rate in 2004 is positively correlated with the probability of divorcing after 2004 with an effect that is statistically significant at the 1 percent level; the higher the level of impatience of the individual, the higher the probability of being divorced. As far as control variables are concerned, contrary to the findings of Light and Ahn (2010), we find that the absolute value of the difference of age between spouses has a negative and statistically significant effect on the probability of divorce, while the difference in the number of years of education does not affect the probability of divorce in a statistically significant way. The area of residence and the size of the municipality do not exert any statistical significant effect, but their sign is as expected. In fact, due to more traditional cultural values, divorce rate is lower in the southern part of the country. ${ }^{10}$

The third specification enriches our analysis including among controls some characteristics of the family of the respondent in order to capture marriage-specific capital (Becker, 1974; Becker et al., 1977; Weiss and Willis, 1997). We include the dummy variables KidsUnder11 and Male-Kids. Estimates show that having kids reduces the probability of divorce in a statistically significant way, while a negative but not significant effect emerges when one of the kids is male. Also in this specification the relationship between impatience and divorce probability is positive and highly statistically significant. The same results are obtained if, instead of controlling for KidsUnder11 and Male-Kids, we include among regressors the total number of kids in the household and a dummy variable for male kids (results not reported and available upon request).

In column (4) we consider also variables describing the economic conditions of the household. While family income should capture gains to marriage deriving from joint consumption (Moffitt, 2000), the share of it contributed by the individual is an indicator of economic independence (which affects the expected gains from divorce) and also captures the individual comparative advantage in market and home production (Becker, 1974). Consistently with theoretical predictions, the decision of ending the relationship is positively affected by the share of the family net labour income contributed by the head of household with an effect that is statistically significant at the 1 percent level. Family Net Labour Income produces a negative but weakly statistically significant effect on the probability of ending the marriage relationship. More important for our research question, even after controlling for these variables, the coefficient on DiscountRate2004 is positive and statistically significant at the 1 percent level. In this specification including the whole set of controls, an increase of the discount rate of one standard deviation increases the probability to divorce of 0.8 percentage points.

${ }^{10}$ We find results that are very similar to those reported in the Table also when, instead of controlling for EducationGap and AgeGap, we control for the age and education of the spouses. 
Table 3. The Determinants of divorce. Time preference: probit model estimates (average marginal effects). Time preference indicator: DiscountRate2004

\begin{tabular}{|c|c|c|c|c|c|}
\hline Variables & (1) & (2) & (3) & (4) & (5) \\
\hline DiscountRate2004 & $\begin{array}{l}0.1734^{* * *} \\
(0.0640)\end{array}$ & $\begin{array}{l}0.1586^{* *} \\
(0.0644)\end{array}$ & $\begin{array}{l}0.1680^{* * *} \\
(0.0631)\end{array}$ & $\begin{array}{l}0.1380^{* *} \\
(0.0603)\end{array}$ & \\
\hline Female & & $\begin{array}{l}0.0437 * * * \\
(0.0102)\end{array}$ & $\begin{array}{l}0.0438 * * * \\
(0.0100)\end{array}$ & $\begin{array}{l}0.0668 \text { *** } \\
(0.0119)\end{array}$ & $\begin{array}{l}0.0694^{* * *} \\
(0.0122)\end{array}$ \\
\hline North & & $\begin{array}{l}0.0031 \\
(0.0109)\end{array}$ & $\begin{array}{l}0.0023 \\
(0.0107)\end{array}$ & $\begin{array}{l}-0.0009 \\
(0.0104)\end{array}$ & $\begin{array}{l}0.0011 \\
(0.0105)\end{array}$ \\
\hline South & & $\begin{array}{l}-0.0041 \\
(0.0115)\end{array}$ & $\begin{array}{l}-0.0026 \\
(0.0112)\end{array}$ & $\begin{array}{l}-0.0079 \\
(0.0109)\end{array}$ & $\begin{array}{l}-0.0036 \\
(0.0109)\end{array}$ \\
\hline Small Municipality & & $\begin{array}{l}-0.0089 \\
(0.0088)\end{array}$ & $\begin{array}{l}-0.0071 \\
(0.0085)\end{array}$ & $\begin{array}{l}-0.0044 \\
(0.0083)\end{array}$ & $\begin{array}{l}-0.0034 \\
(0.0083)\end{array}$ \\
\hline Education Gap & & $\begin{array}{l}0.0008 \\
(0.0016)\end{array}$ & $\begin{array}{l}0.0008 \\
(0.0016)\end{array}$ & $\begin{array}{l}0.0010 \\
(0.0015)\end{array}$ & $\begin{array}{l}0.0010 \\
(0.0016)\end{array}$ \\
\hline Age Gap & & $\begin{array}{l}-0.0029 * * \\
(0.0012)\end{array}$ & $\begin{array}{l}-0.0031^{* * *} \\
(0.0012)\end{array}$ & $\begin{array}{l}-0.0023^{* *} \\
(0.0011)\end{array}$ & $\begin{array}{l}-0.0024^{* *} \\
(0.0011)\end{array}$ \\
\hline Kids Under 11 & & & $\begin{array}{l}-0.0552 * * \\
(0.0251)\end{array}$ & $\begin{array}{l}-0.0413^{*} \\
(0.0229)\end{array}$ & $\begin{array}{l}-0.0423 * \\
(0.0229)\end{array}$ \\
\hline Male-Kids & & & $\begin{array}{l}-0.0153 \\
(0.0308)\end{array}$ & $\begin{array}{l}-0.0171 \\
(0.0283)\end{array}$ & $\begin{array}{l}-0.0134 \\
(0.0279)\end{array}$ \\
\hline Individual Share Family Labour Income & & & & $\begin{array}{l}0.0737 * * * \\
(0.0159)\end{array}$ & $\begin{array}{l}0.0754 * * * \\
(0.0162)\end{array}$ \\
\hline Family Net Labour Income & & & & $\begin{array}{l}-0.0005 \\
(0.0003)\end{array}$ & $\begin{array}{l}-0.0005 \\
(0.0003)\end{array}$ \\
\hline Pseudo R-Squared & 0.0176 & 0.0846 & 0.1361 & 0.2267 & 0.2146 \\
\hline Log likelihood & -211.8343 & -197.3862 & -186.2749 & -166.7530 & -169.3617 \\
\hline Observations & 1,723 & 1,723 & 1,723 & 1,723 & 1,723 \\
\hline
\end{tabular}

In column (5) we estimate the same specification of column (4) without including our impatience indicator. We find that the estimated coefficients for all variables - including age and education gap between spouses, family composition, family net labour income, the individual's net labour income share and other factors that we expect to be correlated with time preferences - are virtually invariant to the inclusion or exclusion of discount rate. Time preferences has a nontrivial effect on the probability of divorce, yet omitting DiscountRate2004 from the model causes only slightly changes in the magnitude of the effects of the other control variables.

In Table 4 we push our analysis of the effect of time preferences on the decision to divorce further by considering five alternative specifications of our model. In all specifications we replicate the specification in column (4) of Table 3, including the whole set of controls (to save space, in Table 4, we do not reports coefficients on these controls which remain almost unchanged).

In the first two columns we enrich our model by including among controls industry dummies and information on family background, respectively. We find that the average marginal effect of impatience is still positive and statistically significant with a magnitude that remains close to 1 percentage point for an 
increase of the discount rate of one standard deviation. As far as the new control variables are concerned, individuals working in the agriculture or industry sector are significantly more likely to divorce with respect to not employed people (retired workers and housewives), while family background (column 2), represented by the level of education of respondent' parents and his/her father occupation industry dummies (not reported), does not contribute in a significant way to the explanation of divorce decision. ${ }^{11}$

Table 4. The Determinants of divorce: probit model estimates (average marginal effects). Further specifications. Time preference indicator: DiscountRate2004

\begin{tabular}{|c|c|c|c|c|c|}
\hline Variables & (1) & (2) & (3) & (4) & (5) \\
\hline DiscountRate2004 & $\begin{array}{c}0.1452 * * \\
(0.0595)\end{array}$ & $\begin{array}{l}0.1289 * \\
(0.0670)\end{array}$ & $\begin{array}{c}0.1409 * * \\
(0.0601)\end{array}$ & $\begin{array}{c}0.1501^{* *} \\
(0.0601)\end{array}$ & $\begin{array}{c}0.1379 * * \\
(0.0573)\end{array}$ \\
\hline Agriculture & $\begin{array}{c}0.0520 * * * \\
(0.0191)\end{array}$ & & & & \\
\hline Manufacture & $\begin{array}{c}0.0313^{* *} \\
(0.0140)\end{array}$ & & & & \\
\hline Public Administration & $\begin{array}{c}0.0157 \\
(0.0147)\end{array}$ & & & & \\
\hline Other Sector & $\begin{array}{c}0.0093 \\
(0.0147)\end{array}$ & & & & \\
\hline Parents Education & & $\begin{array}{c}0.0013 \\
(0.0013)\end{array}$ & & & \\
\hline Share Net Total Income & & & $\begin{array}{c}0.0921 * * * \\
(0.0198)\end{array}$ & & \\
\hline Family Net Total Income & & & $\begin{array}{c}-0.0004 \\
(0.0003)\end{array}$ & & \\
\hline Head of Household Labour Income & & & & $\begin{array}{c}0.0042^{* * *} \\
(0.0011)\end{array}$ & \\
\hline Head of Household Labour Income $\wedge 2$ & & & & $\begin{array}{l}-0.0000 \\
(0.0000)\end{array}$ & \\
\hline Family Labour Income & & & & $\begin{array}{c}-0.0036 * * * \\
(0.0007)\end{array}$ & \\
\hline Family Labour Income ${ }^{\wedge 2}$ & & & & $\begin{array}{c}0.0000^{* * *} \\
(0.0000)\end{array}$ & \\
\hline Predicted Individual Labour Income & & & & & $\begin{array}{c}0.0078 * * * \\
(0.0014)\end{array}$ \\
\hline Predicted Family Labour Income & & & & & $\begin{array}{c}-0.0047 * * * \\
(0.0008)\end{array}$ \\
\hline Pseudo R-Square & 0.2512 & 0.2424 & 0.2288 & 0.2326 & 0.3024 \\
\hline Log likelihood & -161.4692 & -121.0991 & -166.2878 & -165.4745 & -150.4249 \\
\hline Observations & 1,723 & 1,394 & 1,723 & 1,723 & 1,723 \\
\hline $\begin{array}{l}\text { Notes: The Table reports average marg } \\
\text { variable is the dummy DivorceAfter } 20 \\
\text { composition as in Table } 4 \text { specificatio } \\
\text { Family Labour Income. Standard errors } \\
\text { control for birth cohort dummies. The s } \\
10 \text { percent level, respectively. }\end{array}$ & $\begin{array}{l}\text { effects of } \\
\text { In all speci } \\
\text { in columns } \\
\text { rected for he } \\
\text { ols ***, **, }\end{array}$ & $\begin{array}{l}\text { estimates } \\
\text { ns we incl } \\
2 \text { we also } \\
\text { edasticity, } \\
\text { cate that th }\end{array}$ & $\begin{array}{l}\text { verage of ea } \\
\text { ontrols for i } \\
\text { de Individuc } \\
\text { ported in par } \\
\text { ficients are }\end{array}$ & $\begin{array}{l}\text { arginal effec } \\
\text { hual charact } \\
\text { re Family } L \\
\text { es. In all spe } \\
\text { cally signifi }\end{array}$ & $\begin{array}{l}\text { he dependent } \\
\text { s and family } \\
\text { Income and } \\
\text { tions we also } \\
\text { t the } 1,5 \text { and }\end{array}$ \\
\hline
\end{tabular}

The last three columns report some more flexible specifications in which we look at different measures or functional forms for our economic variables.

In column (3) we redefine our measure of individual and family net income by considering the total income, that is the sum of labour income plus property income from real-estate and financial assets. We find that also when considering the total income, the share contributed by the head of household exerts a positive and statistically significant effect while the family net total income produces a negative but not

\footnotetext{
${ }^{11}$ In the specification in column (2), including control variables for individual family background, the sample reduces to 1,394 observations because of some missing values in such controls.
} 
statistically significant effect. Again, the effect of time preferences remains positive and statistically significant.

In column (4) we propose a different functional form including the square of both individual and family net labour income. ${ }^{12}$ Individual discount rate exerts a positive and statistically significant effect with an almost unchanged magnitude. We find that family level of net labour income decreases the probability of divorcing at an increasing rate, while the individual level of net family income is linked to the probability to divorce by a linear relationship.

In the last specification, following Light and Ahn (2010), we replace our economic variables with their predicted values, given that these variables are likely to be endogenous to the expected probability of divorce. Our results are consistent with those emerging from the literature: data shows that individual predicted income exerts a positive and statistically significant effect on the probability of divorce while the effect of family predicted income is negative and significant. When considering individual predicted share of income (computed as the ratio between individual and family predicted income) the coefficient of individual predicted share is still positive and significant at the 1 percent level, while the effect of family predicted income becomes not statistically significant. Also in this specification the relationship between individual discount rate in 2004 and the probability to divorce after 2004 is positive and statistically significant.

\section{Divorce and Time and Risk Preferences}

As shown in Castillo et al. (2011) and De Paola (2012), when analysing the effect of time preferences, it might be important to control for individual risk preferences since discount rates might reflect differences in risk preferences. Andreoni and Sprenger (2012) argue that, since present is known while future is risky, it might be difficult to disentangle the effects of time and risk preferences. Then, uncontrolled risk may drive our results: less patient individuals might also be more risk oriented and, as shown by Light and Ahn (2010), less risk averse subjects are more likely to experience separation or divorce.

Unfortunately there is no information regarding individual risk attitudes in the 2004 wave of the SHIW. This information is instead available in the 2010 wave. In this section, we use these data with the aim of both investigating whether our results are robust once we control for risk preferences and of providing some new evidence on the effect that risk preferences produce on marriage stability. The relationship between risk aversion and divorce has been highlighted by Ligh and Ahn (2010) presenting a model in which they show how a married person's relative risk tolerance affects his/her choice between the less risky option of remaining married and the riskier option of divorcing. From their empirical analysis, based on US data, it emerges that individuals with a higher degree of risk tolerance are more

\footnotetext{
${ }^{12}$ As regards individual income, in this specification we control for the individual net labour income instead of for the share contributed by him/her.
} 
likely to experience divorce. To the best of our knowledge, there are no other works analysing this relationship and we think it is valuable to shed some more light on this issue providing evidence for another country.

In the 2010 wave of the SHIW, as well as in the 2004 one, information on time preferences is available only for the heads of household. We use both the panel and the non-panel component of the sample and focus our attention on subjects that in 2010 were either married or divorced, ending up with a sample of 3,661 observations. ${ }^{13}$

Our dependent variable is Divorce, a dummy variable taking the value of 1 if in 2010 the marital status of the individual is "separated or divorced" and the value of 0 if the marital status is married. About $11.20 \%$ of the heads of household in our sample are separated or divorced.

We compute our measure of impatience, DiscountRate, using the answers to a question of the 2010 survey, similar to the one asked in 2004, with the only difference that among the available alternatives for the percentage of the sum that respondents would be willing to give up to have immediately the money won there are $0,2,5,10$ or 20 percent. $^{14}$ The mean value of this variable is 0.0618 with a standard deviation of 0.0682 .

To investigate the role played by risk attitudes in divorce decisions we use a question asking individuals to choose the amount of money they would like to invest in a hypothetical lottery where there is the chance to double the invested money but it is equally possible to lose half of the amount invested, depending on a coin toss (tails mean win, heads mean loss). More precisely, individuals are posed with the following question: "Imagine you can take part in a lottery in which for every euro invested, you can either double your money (win 1 euro) or lose half of it (lose 50 cents), depending on a coin toss (tails you win, heads you lose). How much money would you invest?”.

Using answers to this question, we built two measures of individual risk aversion. The first, AbsoluteRiskAversion, is an Arrow-Pratt index of absolute risk aversion. ${ }^{15}$ This index takes values in the range 0.000012 (for individuals willing to invest 100.000 euros, the maximum value in our sample) and $1.5^{16}$ (for those who are unwilling to invest any amount of money), and takes an average value of

\footnotetext{
${ }^{13}$ This wave covers 7,951 households composed of 19,836 individuals and the information on time preferences and risk aversion is available for 5,128 heads of household. 801 and 666 individuals were widows and singles, respectively, in 2010, and have been excluded from our sample.

${ }^{14} 28.38 \%$ of respondents refuse to give up any amount of money, waiting to have the whole amount the following year. 19.94\% of respondents decide to give up 2 percent and 18.38\% decide to give up 5 percent. Finally, 17.97\% and $15.32 \%$ of heads of household give up 10 and 20 percent, respectively.

${ }^{15}$ We obtain a measure of the Arrow-Pratt index of absolute risk aversion for each individual. Let $\mathrm{w}_{\mathrm{i}}$ denote household i's endowment, and $\mathrm{u}_{\mathrm{i}}\left(\right.$.) be the (lifetime) utility function and let $\vec{P}_{i}$ be the security random return for individual $\mathrm{i}$, taking values $2 \mathrm{Z}_{\mathrm{i}}$ and $\mathrm{Z}_{\mathrm{i}} / 2$ with equal probability. The maximum purchase price is thus given by $u_{i}\left(w_{i}\right)=\frac{1}{2} u_{i}\left(w_{i}+2 Z_{i}\right)+\frac{1}{2} u_{i}\left(w_{i}+\frac{Z_{i}}{2}\right)=E u_{i}\left(w_{i}+\vec{P}_{i}\right)$. We take the second-order Taylor expansion of the second equality of this equation around $w_{i}$ and obtain: $R_{i}\left(w_{i}\right) \cong \frac{-u_{i}{ }^{\prime \prime}\left(w_{i}\right)}{u_{i}{ }^{\prime}\left(w_{i}\right)}=2\left(2 Z_{i}+\frac{Z_{i}}{2}\right) /\left(4 Z^{2}+\frac{Z^{2}}{4}\right)$.

${ }^{16}$ Since the Arrow-Pratt index of risk aversion is not defined for individuals refusing to invest any amount of money, for them we have imputed a value of 1.5. We have also experimented imputing alternative values (always
} 
0.6398466 (standard deviation 0.6865863). The second measure of individual risk aversion is the dummy variable Averse, with the value of 1 for respondents who refuse to invest any money and 0 otherwise. Based on this indicator, about 35\% of the individuals in our sample are considered risk averse.

It is worthwhile to notice that the larger sample and the information on risk attitudes come at the price of having measures of impatience and risk attitudes that are revealed in the same moment in which the marital status of respondents is observed. This could give rise to reverse causality problems. Nevertheless, results discussed in the previous section reassure us that the relationship between time preferences is unlikely to originate exclusively from the effect that marital status produces on this type of individual attitudes.

Table 5 presents average marginal effects of probit model estimates. The first column replicates specification (1) of Table (3) in which we only consider time preferences among regressors. We find a positive correlation, statistically significant at the 5 percent level that is very similar in magnitude to that found using the panel sample. ${ }^{17}$ An increase of one standard deviation in DiscountRate is correlated to an increase in the probability of being divorced of about 1 percentage point. We have also replicated specification (4) of Table 3, including the full set of controls, and again we find an effect of time preferences that is similar to that found considering the panel sample (not reported and available upon request).

Starting from column (2), we turn our attention to the role played by risk aversion. Firstly, we only consider among regressors our measure AbsoluteRiskAversion. We find that individuals who display a higher degree of absolute risk aversion are less likely to divorce (the effect is statistically significant at the 1 percent level). An increase of one standard deviation in our measure of AbsoluteRiskAversion increases the probability of being divorced by about 1.5 percentage points. This effect persists also when we add among regressors the full set of our controls (not reported).

In column (3) we present a specification in which we consider both risk and time preferences. Both these variables show statistically significant coefficients: again impatience is positively correlated with the dependent variable (at the 10 per cent level), while risk aversion shows a negative sign, statistically significant at the 1 per cent level. Remarkably, the magnitude of the effects of time and risk preferences is very similar to that obtained when considering separately each variable.

In column (4) we add a number of individual predetermined characteristics (gender, year of birth cohort dummies -not reported-, age, residential area, a dummy variable indicating whether individuals live

higher than the value obtained for individuals wanting to invest 1 euro). Independently of the imputed values our results remain qualitatively unchanged.

${ }^{17}$ However, in comparing these effects to those found previously, we have to consider that while in the previous section we were estimating the probability that a person who was married in 2004 had experienced divorce in the six following years, here we are looking at the probability of being divorced in a certain point of time (in 2010). In fact, in section 3, conditional on all the covariates, the increase of 1 percentage point in the probability of divorcing due to an increase of one standard deviation in the discount rate, compared to a divorce rate of 2.25 percentage points among individuals with discount rate equal to zero, represents a 44 percent larger likelihood of divorcing. Instead, in the 2010 analysis, the increase of 1 percentage point in the probability of divorcing due to an increase of one standard deviation in the discount rate, compared to a divorce rate of 9.62 percentage points among individuals with discount rate equal to zero, represents a 10 percent larger likelihood of divorcing. 
in a small town, education). Adding these controls increases the magnitude of the effect produced by time preferences, while the coefficient of our measure of risk aversion remains almost the same.

Table 5. The Determinants of divorce. Time and Risk preferences: probit model estimates (average marginal effects). Risk aversion indicator: AbsoluteRiskAversion

\begin{tabular}{|c|c|c|c|c|c|c|}
\hline & (1) & (2) & (3) & (4) & (5) & (6) \\
\hline Discount Rate & $\begin{array}{c}0.1528 * * \\
(0.0741)\end{array}$ & & $\begin{array}{l}0.1454 * \\
(0.0742)\end{array}$ & $\begin{array}{c}0.1935^{* * *} \\
(0.0746)\end{array}$ & $\begin{array}{c}0.1649 * * \\
(0.0678)\end{array}$ & $\begin{array}{c}0.1218^{* *} \\
(0.0622)\end{array}$ \\
\hline AbsoluteRiskAversion & & $\begin{array}{c}-0.0225 * * * \\
(0.0077)\end{array}$ & $\begin{array}{c}-0.0220 * * * \\
(0.0077)\end{array}$ & $\begin{array}{c}-0.0190 * * \\
(0.0075)\end{array}$ & $\begin{array}{c}-0.0128 * \\
(0.0066)\end{array}$ & $\begin{array}{c}-0.0119 * * \\
(0.0060)\end{array}$ \\
\hline Female & & & & $\begin{array}{c}0.1220 * * * \\
(0.0104)\end{array}$ & $\begin{array}{c}0.0876 * * * \\
(0.0088)\end{array}$ & $\begin{array}{c}0.1314 * * * \\
(0.0088)\end{array}$ \\
\hline North & & & & $\begin{array}{l}0.0235^{*} \\
(0.0127)\end{array}$ & $\begin{array}{c}0.0066 \\
(0.0115)\end{array}$ & $\begin{array}{l}-0.0062 \\
(0.0104)\end{array}$ \\
\hline South & & & & $\begin{array}{c}-0.0363^{* *} \\
(0.0154)\end{array}$ & $\begin{array}{l}-0.0119 \\
(0.0140)\end{array}$ & $\begin{array}{c}-0.0241 * \\
(0.0127)\end{array}$ \\
\hline Small & & & & $\begin{array}{c}-0.0335 * * * \\
(0.0119)\end{array}$ & $\begin{array}{c}-0.0317 * * * \\
(0.0104)\end{array}$ & $\begin{array}{c}-0.0253 * * * \\
(0.0093)\end{array}$ \\
\hline Education & & & & $\begin{array}{c}0.0011 \\
(0.0013)\end{array}$ & $\begin{array}{c}0.0016 \\
(0.0011)\end{array}$ & $\begin{array}{c}0.0008 \\
(0.0014)\end{array}$ \\
\hline Age & & & & $\begin{array}{c}0.0012 \\
(0.0015)\end{array}$ & $\begin{array}{c}0.0004 \\
(0.0013)\end{array}$ & $\begin{array}{l}-0.0002 \\
(0.0012)\end{array}$ \\
\hline Kids Under 11 & & & & & $\begin{array}{c}-0.1779 * * * \\
(0.0126)\end{array}$ & $\begin{array}{c}-0.1234 * * * \\
(0.0125)\end{array}$ \\
\hline Male-Kids & & & & & $\begin{array}{c}-0.1142 * * * \\
(0.0200)\end{array}$ & $\begin{array}{c}-0.0739 * * * \\
(0.0179)\end{array}$ \\
\hline Share Family Income & & & & & & $\begin{array}{c}0.2316^{* * *} \\
(0.0180)\end{array}$ \\
\hline Family Income & & & & & & $\begin{array}{c}-0.0009 * * \\
(0.0004)\end{array}$ \\
\hline Pseudo R-squared & 0.0016 & 0.0033 & 0.0048 & 0.0848 & 0.3070 & 0.4437 \\
\hline Log likelihood & -1281.6854 & -1279.4741 & -1277.5912 & -1174.9094 & -889.5972 & -705.6065 \\
\hline
\end{tabular}

Notes: The Table reports average marginal effects of Probit estimates (the average of each marginal effect). The dependent variable is the dummy Divorce. Standard errors, corrected for heteroskedasticity, are reported in parentheses. Year of birth dummies included in specifications (4), (5) and (6). The symbols ***, **, * indicate that the coefficients are statistically significant at the 1,5 and 10 percent level, respectively.

As education might not be sufficient to control for differences in cognitive abilities, which are typically correlated with both time and risk preferences (Dohmen et al. 2010), we have also considered answers to a question of the 2010 wave of the SHIW aimed at understanding individual logical and computational skills. ${ }^{18}$ This variable does not affect divorce probability and leaves our main results qualitatively unchanged (results not reported and available upon request).

In column (5) we also consider among controls two variables aimed at describing family composition (KidsUnder11 and Male-Kids observed in 2010). Our main findings remain qualitatively unchanged. Finally, in column (6) we add controls for individual and family economic conditions. Also in this case, we find that more impatient and more risk prone individuals are more likely to experience

\footnotetext{
18 Individuals are asked the following question: "Imagine leaving 1,000 euros in a current account that pays $1 \%$ interest and has no charges. Imagine that inflation is running at $2 \%$. Do you think that if you withdraw the money in a year's time you will be able to buy the same amount of goods as if you spent the 1,000 euros today? Possible answers are: "Yes”; “No, I will be able to buy less"; "No, I will be able to buy more”; "I do not know”. Using answers to this question, we have built a dummy variable for individuals providing the correct answer.
} 
divorce. After including the full set of our controls, an increase of one standard deviation in DiscountRate increase the probability of being divorced by 0.8 percentage points.

Control variables also behave as discussed in the previous section. Some coefficients that were not statistically significant, now gain statistical power. For example, the dummy variable South, is again negative but now it becomes statistically significant at the 10 per cent level, implying that people living in the southern part of the country, probably due to cultural factors, show lower divorce rates. In addition, having male children also produces a negative and statistically significant impact. However, it is worthwhile to notice that measures of family composition and individual and family economic conditions are less reliable and more subject to endogeneity problems in the 2010 sample as they refer to the same year in which we observe whether respondents are married or divorced.

In Table 6 we replicate specifications (2)-(5) of Table 5 using as a measure of risk aversion the dummy variable Averse. Again, more impatient individuals are more likely to be divorced. The statistical significance and the magnitude of the coefficient on DiscountRate remains almost the same as that obtained when controlling for AbsoluteRiskAversion. We also find that people who refused to invest any money in the risky lottery are less likely to experience divorce, with an effect that is statistically significant at the 1 or at the 5 percent level depending on specifications. When adding all our controls (column (5)), a very risk averse individual is about 2.16 percentage points less likely to have ended his/her marriage compared to persons who have decided to invest an amount of money in the risky lottery.

Table 6. The Determinants of divorce. Time and Risk preferences: probit model estimates (average marginal effects). Risk aversion indicator: Averse

\begin{tabular}{|c|c|c|c|c|c|}
\hline & (1) & $(2)$ & (3) & (4) & (5) \\
\hline Discount Rate & & $\begin{array}{c}0.1456^{* *} \\
(0.0741)\end{array}$ & $\begin{array}{c}0.1955^{* * *} \\
(0.0745)\end{array}$ & $\begin{array}{c}0.1666^{* *} \\
(0.0677)\end{array}$ & $\begin{array}{c}0.1235 * * \\
(0.0622)\end{array}$ \\
\hline Averse & $\begin{array}{c}-0.0331 * * * \\
(0.0112)\end{array}$ & $\begin{array}{c}-0.0324 * * * \\
(0.0112)\end{array}$ & $\begin{array}{c}-0.0282 * * * \\
(0.0109)\end{array}$ & $\begin{array}{c}-0.0228 * * \\
(0.0097)\end{array}$ & $\begin{array}{c}-0.0216^{* *} \\
(0.0089)\end{array}$ \\
\hline Individual Characteristics & NO & NO & YES & YES & YES \\
\hline Family Composition & NO & NO & NO & YES & YES \\
\hline $\begin{array}{l}\text { Individual and Family Economic } \\
\text { Conditions }\end{array}$ & NO & NO & NO & NO & YES \\
\hline Pseudo R-squared & 0.0035 & 0.0049 & 0.0849 & 0.3078 & 0.4445 \\
\hline $\log$ & -1279.3172 & -1277.4251 & -1174.7675 & -888.66475 & -704.5572 \\
\hline Observations & 3661 & 3661 & 3661 & 3661 & 3618 \\
\hline
\end{tabular}

All in all, our results show that the positive effect of impatience on divorce probability, found in the previous section, is not due to correlation between time and risk preferences. Also controlling for risk aversion, we find that more impatient individuals are more likely to experience divorce. In addition, we confirm the results found by Light and Ahn (2010) for US: individuals with a higher level of absolute risk aversion are less likely to divorce given the riskier nature of this decision with respect to the alternative of remaining married. 


\section{Concluding remarks}

An increasing psychological and economical literature investigates the role of a number of non-cognitive traits on individual outcomes. However, while the effect of these variables on certain outcomes, such as academic results, labour market performance, health, has been considered by a large number of works, other domains are almost ignored.

In this paper, we have contributed to close this gap by focusing on the relationship between time preferences and separation/divorce decisions. Time preferences can affect marriage stability through a number of different channels. Time preferences can affect marriage stability through the initial quality of the match: impatient individuals may invest less in searching activity and end up with a worse match, which would affect marriage duration since unanticipated shocks are less destabilizing if partners are well matched. In addition, patience might improve daily interactions between the spouses with positive effects on the duration of their marriage. Finally, time preferences can influence the way individuals manage unanticipated shocks that deteriorate their relationship: more patient individuals may be more inclined to sustain the immediate costs deriving from the shock and wait for an improvement in the relationship or invest more (for example in terms of time and energies) to re-establish harmony.

We have empirically assessed the relationship between time preferences and divorce decision using an Italian data-set that allows us to build a measure of time preferences based on a hypothetical financial situation in which individuals have to decide how much money to give up in order to receive a certain amount of money today instead of in one year's time. For couples that were married in 2004, we estimate the probability of divorcing in the next 6 years. Controlling for a number of individual characteristics, we find a positive correlation between the probability of being separated/divorced and impatience. More precisely an increase of one standard deviation in individual discount rate increases the probability of experiencing divorce by almost one percentage point.

This result is consistent with findings highlighted by Compton (2009), showing for US that more impatient individuals are more likely to divorce. Compared to Compton's analysis, which relies on indirect measures of time preferences, such as smoking or contraceptive use, our study has the advantage of using direct measures of time preferences that are less likely to be correlated to other confounding variables.

We have also checked whether our estimates are robust when we include among controls a measure of individual risk aversion. We find that taking constant individual risk aversion, time preferences still produce a statistically significant effect on the probability of divorce. In line with results found by Light and Ahn (2010) for US, we find a positive relationship between risk tolerance and divorce decision. 


\section{References}

Ahn T. (2010), Attitudes toward risk and self-employment of young workers, Labour Economics, 7(2), 434-442.

Almlund M., Duckworth A., Heckman J., Kautz T. (2011), Personality psychology and economics, IZA DP No. 5500.

Anderhub V., Güth W., Gneezy U., Sonsino D. (2001), On the Interaction of Risk and Time Preferences: An Experimental Study, German Economic Review, 2(3), 239-253.

Anderson L., Mellor J. (2008), Predicting health behaviors with an experimental measure of risk preference, Journal of health economics, 7(5), 1260-1274.

Andreoni J. and Sprenger C. (2012), Risk preferences are not time preferences, American Economic Review, 102(7), 3357-3376(20).

Becker, G. S. (1974), A Theory of Marriage. In The Economics of the Family: Marriage, Children, and Human Capital, ed. Theodore W. Schultz, 299-344. Chicago: University of Chicago Press.

Becker, G. S.; Landes, E. and Michael, R. (1977), An Economic Analysis of Marital Instability. Journal of Political Economy 85, 1141-87.

Belzil, C., and M. Leonardi (2007), Can risk aversion explain schooling attainments? Evidence from Italy, Labour Economics, 14, pp.957-970.

Burdett K. and Cole M., 1999, Long-term partnership formation: Marriage and employment. Economic Journal 109, no. 456:F307-F334.

Castillo, M. et al. (2011), The Today and Tomorrow of Kids, Journal of Public Economics, 95(11), 13771385.

Cadena, B. and Keys, B. (2011), Human Capital and the Lifetime Costs of Impatience, Unpublished manuscript, Harris School of Public Policy, University of Chicago.

Compton J. (2009), Why do Smokers Divorce? Time Preference and Marital Stability, WP University of Manitoba,

Caner, A., C. Okten (2010), Risk and career choice: Evidence from Turkey, Economics of Education Review, 29, pp.1060-1075.

Courtemanche C., Heutel, J. McAlvanah G. (2011), Impatience, Incentives, and Obesity, NBER working paper

De Paola, M. (2012), The Determinants of Risk Aversion: the Role of Intergenerational Transmission, German Economic Review, 14(2), pp. 214-234.

De Paola, M. and Gioia F. (2012), Risk Aversion and Field of Study Choice: The Role of Individual Ability, Bulletin of Economic Research, vol. 64, pp. s193-s209

De Paola, M. and Gioia F. (2013), Impatience And Academic Performance. Less Effort And Less Ambitious Goals, WP Dipartimento Scienze Economiche, Statistiche e Finanziarie, n.2.

De Rose A. (1992), Socio-economic Factors and Family Size as Determinants of Marital Dissolution in Italy, European Sociological Review 8, 71-91.

Della Vigna, S. and Paserman, M. D. (2005), Job Search and Impatience, Journal of Labor Economics, vol. 23, n³, pp. 527-588

Dohmen T. and Falk A. (2011), Performance Pay and Multidimensional Sorting: Productivity, Preferences, and Gender, American Economic Review, American Economic Association, vol. 101(2), 556-90.

Dohmen T., Khamis M., Lehmann H., (2010), Risk Attitudes and the Incidence of Informality among Workers: Evidence from a Transition Country, ESCIRRU Working Papers 22, DIW Berlin, German Institute for Economic Research.

Dohmen T., Falk A, Huffman, D. and Sunde U. (2010), Are Risk Aversion and Impatience Related to Cognitive Ability?, American Economic Review, 100, 1238-1260.

Drago, F. (2006), Career Consequences of Hyperbolic Time Preferences, IZA Discussion Papers Series $\mathrm{N}^{\circ} 2113$

Ferro I. and Vignoli D. (2009), Rising marital disruption in Italy and its correlates, Demographic Research, Max Planck Institute for Demographic Research, Rostock, Germany, vol. 20(4), 11-36.

Golsteyn, B. et al. (2012), Time Preferences and Lifetime Outcomes, IZA

Jaeger D., Dohmen T., Falk A. and Huffman D. Sunde U. Bonin H., (2010), Direct Evidence on Risk Attitudes and Migration, The Review of Economics and Statistics, MIT Press, vol. 92(3), 684-689. 
Johnson, W. and J. Skinner (1986), Labor Supply and Marital Separation. American Economic Review, 76(3): 455-469

Lehrer, E.L. (2008), Age at marriage and marital instability: revisiting the Becker-Landes-Michael hypothesis, Journal of Population Economics, 21(2): 463-484.

Light, A., and T. Ahn. (2010), Divorce as Risky Behavior, Demography, 47(4), 895-921.

Lundberg, S. and E. Rose (2003), Child Gender and the Transition to Marriage. Demography, 40(2): 333350.

Moffitt, R. (2000), Female Wages, Male Wages, and the Economic Model of Marriage: The Basic Evidence., 302-19, in The Ties That Bind: Perspectives on Marriage and Cohabitation, edited by Linda J. Waite. Aldine de Gruyter.

Morgan, S. and M. Pollard (2002), Do Parents of Girls Really Have a Higher Risk of Divorce? Revisiting Father Involvement and Marital Stability. Duke University, Department of Sociology discussion paper.

Oppenheimer, V. K. (1997), Women's Employment and the Gain to Marriage: the Specialization and Trading Model. Annual Review of Sociology, 23: 431-453.Perez-Arce, F. (2011), The Effect of Education on Time Preferences, RAND Working Paper Series WR- 844.

Pollmann, D., Dohmen, T., Palm, F. (2012), Robust Estimation of Wage Dispersion with Censored Data: An Application to Occupational Earnings Risk and Risk Attitudes, IZA Discussion Papers 6447.

Salvini S. and Vignoli D., (2011), Things change: Women's and men's marital disruption dynamics in Italy during a time of social transformations, 1970-2003, Demographic Research, Max Planck Institute for Demographic Research, Rostock, Germany, vol. 24(5), 145-174.

Samuelson, P. A. (1937), A Note on Measurement of Utility, Review of Economic Studies, 4(2), 155-161.

Schmidt, L. (2008), Risk Preferences and the Timing of Marriage and Childbearing, Demography, 45, 439-60.

SHIW dataset, 2010 wave and 2004 wave, http://www.bancaditalia.it/statistiche/indcamp/bilfait

Spivey, C. (2010), Desperation or Desire? The Role of Risk Aversion in Marriage, Economic Inquiry, 48(2), 499-516

Stevenson, B. (2007) “The Impact of Divorce Laws on Marriage-Specific Capital”, Journal of Labor Economics, 25(1), pp.75-94.

Sutter, M. et al. (2011), Impatience and Uncertainly: Experimental Decisions Predict Adolescents Field Behavior, forthcoming American Economic Review

Ventura, L. (2003), Direct Measures of Time Preference, Economic and Social Review, 34(3), 293-310

Weiss, Y. and Willis R. (1997), Match Quality, New Information and Marital Dissolution., Journal of Labor Economics, 15(1). S293-S329. 